\title{
Structural, biochemical and functional aspects of sperm-oocyte interactions in pigs
}

\author{
D. Rath ${ }^{*}$, E. Töpfer-Petersen ${ }^{3}$, H.-W. Michelmann ${ }^{3}$, P. Schwartz ${ }^{4}$, D. von
} Witzendorff ${ }^{2}$, S. Ebeling ${ }^{2}$, M. Ekhlasi-Hundrieser ${ }^{2}$, E. Piehler ${ }^{2}$ Petrunkina $A^{2}$, and R. Romar ${ }^{1}$

'Institute for Animal Breeding, Mariensee, (FAL) 31535 Neustadt, Cermany; ${ }^{2}$ Institute for Reproductive Medicine, School of Veterinary Medicine, Hannover, Buenteweg 15, 30559 Hannover, Cermany; ${ }^{3}$ Department of Obstetrics and Cynaecology, Georg-August-University, Robert-Koch Str. 40, 37075Cöttingen; ${ }^{4}$ Department of Anatomy, Georg-August-University, Kreuzbergring 36, 37075

Göttingen, Germany

Polyspermic fertilization is still a major issue in porcine IVF systems. New information is available to characterize the zona pellucida (ZP) at different developmental stages by scanning electron microscopy (SEM) and by confocal microscopy to show the distribution of ZP glycoproteins. SEM images indicated no differences between in vivo and in vitro matured oocytes; however a change in the surface structure between immature and matured oocytes, as well as between mature oocytes and preimplantation embryos was obvious. In addition, spermatozoa were more tightly fixed in the ZP of in vivo produced compared to the ZP of in vitro produced embryos. The ZP undergoes biochemical changes during maturation prior to fertilization. The acidity of the $Z P$ increases during maturation as indicated by a shift of $1.3 \mathrm{pl}$ units for ZPB/ZPC and $0.8 \mathrm{pl}$ units for ZPA in 2D gel electrophoresis, which is based on increasing sulfation of the oligosaccharides during maturation. Mass spectrometry in combination with in-gel deglycosylation allowed the mapping of new glycosylation sites. Functionality of the ZP also depends on its maturation status. Induction of the acrosome reaction was delayed when capacitated spermatozoa were exposed to immature oocytes.

\section{Introduction}

Fertilization is the most prominent event in life, when male and female gametes fuse together to initiate the life of a new individual. In mammals, fertilization results from three major events during sperm-oocyte interaction. In the first step, the sperm cell binds to the outer glycoprotein layers of the oocyte. The sperm cell then penetrates the zona pellucida (ZP) and finally it binds to and fuses with the oolemma, which underlies the ZP. This triggers the cortical reaction, and subsequent zona hardening prevents polyspermic penetrations. Gamete recognition, binding and fusion are highly regulated processes that involve a number of biochemical processes (Jansen et al., 2001). Although many molecules are known to participate in fertilization, it is still difficult to attribute a particular molecule to a certain function. 
After the sperm cell has undergone a series of membrane changes, summarized as sperm capacitation, it binds to the ZP. The primary interaction with the sperm cell is reversible. Several sperm proteins, like galactosyltransferase (GalTase) (Shur et al., 1988; Gong et al, 1995), sp56 (Blei and Wassarman 1990; Cheng et al., 1994; Bookbinder et al., 1995), zona receptor kinase (Leyton et al., 1992; Burks et al., 1995) and spermadhesins (Sanz et al., 1992a; Dostalova et al., 1995; Töpfer-Petersen and Calvete, 1995), are involved. The primary binding induces the acrosome reaction. During this process the sperm plasma membrane and the outer acrosome membrane fuse and acrosomal enzymes are released to assist in penetration of the ZP (Yanagimachi, 1994). In parallel, secondary irreversible binding of zona glycoproteins and different specific sperm proteins occur.

In recent years, much progress was made in in vitro production techniques to elucidate structural, biochemical and functional steps of sperm-oocyte interaction. Although offspring were produced from in vitro derived embryos, the mechanism of fertilization is only partly understood. In the porcine, in vitro production failures are commonly due to polyspermic fertilization, and chances for successful in vitro fertilization (IVF) are much higher in oocytes matured in vivo compared to oocytes matured in vitro (Kouba et al., 2000). Oocytes have to resume meiosis to reach the metaphase II stage, and in parallel, the cytoplasm as well as the oocyte organelles must finalize their maturation process. As our understanding of in vitro interaction of spermatozoa and ZP is incomplete, it remains open whether or not the ZP also must undergo maturation in order to become fully competent.

\section{Zona pellucida}

The ZP is a highly specialized, three-dimensional matrix with a thickness of $16 \mu \mathrm{m}$ in pigs and it contains 30-33ng of glycoproteins (Nakano and Yonezawa, 2001). The ZP mediates speciesspecific recognition and regulates the interaction with potential fertilizing spermatozoa, which must pass through the ZP before they fuse with the oolemma. Finally, the ZP protects the oocyte and the pre-implantation embryo. Recognition between both gametes is essential for fertilization, and in most species, distinct oligosaccharides of zona glycoproteins interact with complementary carbohydrate-binding proteins of the sperm head (Sinowatz et al., 1997). Such a basic mechanism is conserved throughout evolution (Töpfer-Petersen, 1999). The ZP is composed of three highly specific glycoproteins, which contain a high amount of glycans. A ZP module of about 260 amino acids is shared by all ZP glycoproteins (Bork and Sander, 1992). Additionally, a trefoil domain and a cysteine-rich, 45 amino acid stretch with a 22 amino acid signature sequence, is located $\mathrm{N}$-terminally to the ZP module in the ZPB glycoproteins family (Bork, 1993). Because different types of processing of the polypeptide chain and post-translational modifications e.g. glycosylation and sulfation occur (Wassarman, 1990), proteins of different molecular weight are produced in different species and a classification based on molecular weight is not useful. Therefore, glycoproteins are designated ZPA, ZPB and ZPC, according to the coding genes (Harris et al., 1994). In porcine ZP, ZPB and ZPC glycoprotein oligomers assemble the ZP architecture, whereas ZPA glycoproteins participate in late fertilization events. This was confirmed by recent investigations of the distribution of glycoproteins in the ZP, employing specific fluorescence labelled antibodies against porcine ZPA, ZPB and ZPC (E. Töpfer-Petersen and D. Rath, unpublished). Fig. 1 presents different distributions of glycoprotein families that vary among maturation stages in vitro.

The carbohydrate part of the ZP glycoproteins consists of neutral and highly sulphated/ sialylated $\mathrm{N}$ - and $\mathrm{O}$-glycans. In the porcine, $\mathrm{N}$-linked glycans belong mainly to the complex bi-, tri- and tetra-antennary type with an $\alpha 1,6$ fucosylated trimannosyl core. Both $\mathrm{N}$-linked and O-linked 


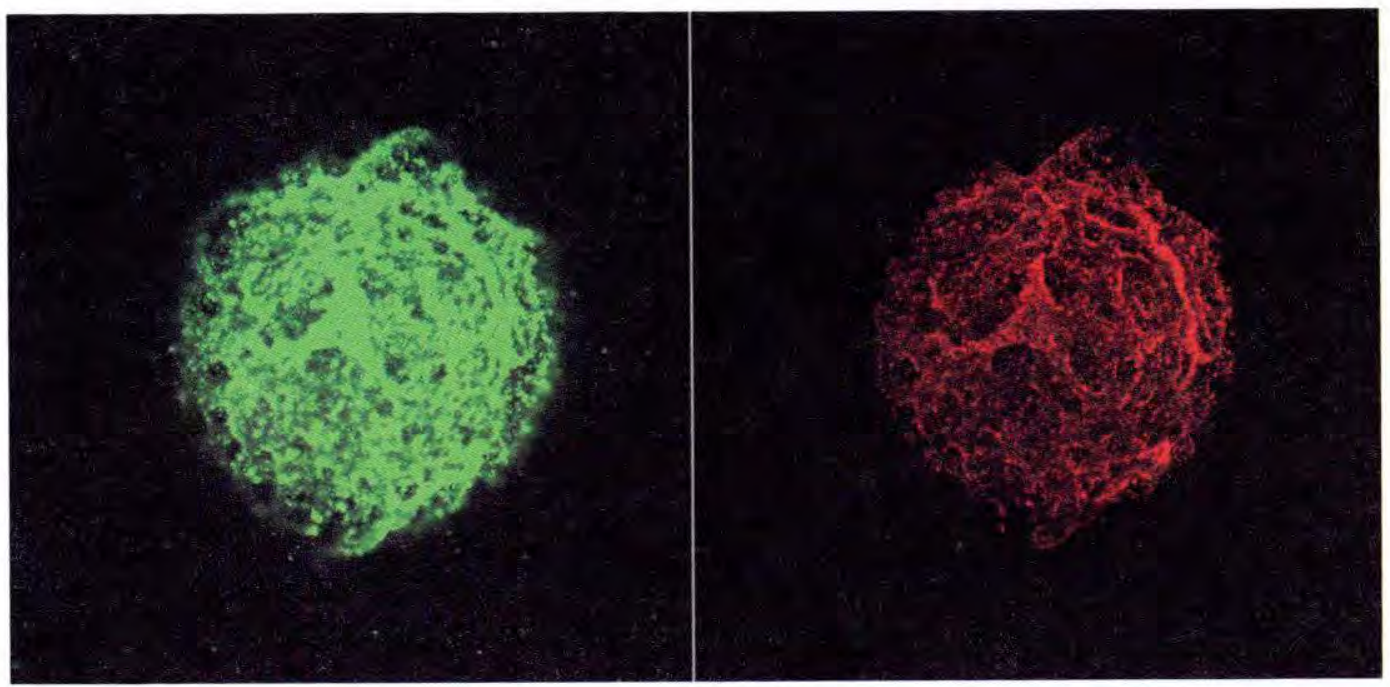

Fig. 1 Confocal microscope image of ZPA (green) and ZPC (red) glycoproteins. Porcine oocyte $48 \mathrm{~h}$ after onset of in vitro maturation

chains are elongated by tandemly arranged $\mathrm{N}$-acetyllactosamine repeats (Nakano and Yonezawa, 2001; Takasaki et al., 1999). ZPA is the largest ZP protein, which contains six potential Nglycosylation sites. The number of O-glycosylated sites of ZPA still remains unknown. In our latest experiments, we investigated the distribution of $\mathrm{N}$-glycosylation sites and the oligosaccharide pattern of the porcine ZPA glycoproteins of immature oocytes (von Witzendorff et al., 2004). In-gel deglycosylation of electrophoretically separated ZPA protein allowed the analysis of the glycan structures by MALDI-ToF-mass spectroscopy. The major N-glycans were neutral bi-antennary structures. Complex oligosaccharides carrying $\mathrm{N}$-acetyllactosamine repeats were minor components and were mostly sialylated. Glycan mapping showed the occurrence of a pentamannosyl glycan in the ZPA protein that was absent in the ZPB and ZPC proteins. By combination of tryptic digestion of the endo-ß-galactosidase-treated ZP glycoproteins mixture and in-gel digestion of ZPA with lectin-affinity chromatography and reverse-phase HPLC, five out of six N-glycosylation sites at Asn (Asparagine) 84/93, Asn 268, Asn 316, Asn 323 and Asn 530 were identified by mass spectroscopy. Only the glycosylated site at Asn 530 was located in the ZP-domain.

Porcine ZPA (pZP2/pZP4) has a conserved proteolytic clip between $\mathrm{A}_{168}$ and $\mathrm{D}_{169^{\circ}}$. Following fertilization, ZPA proteins are cleaved into the disulfide-bridged N-terminal 25 kDa polypeptide (pZP4) and the 65-kDa polypeptide (pZP2), which are separated by reduction of the disulfide into both protein units (Hasgawa et al., 1994). This mechanism was also shown in human (Bauskin et al., 1999), bovine (Iwamoto et al., 1999) and frog oocytes (Lindsay and Hedrick, 2004). In vivo, a protease released from the cortical granules seems to be responsible for processing of the ZPA glycoproteins (Zhang et al., 1991). Furthermore, in the bovine, oxidation of cysteine residues to cysteines occurs during fertilization. Thus, protein processing and formation of inter- and intramolecular disulfide bonds are essential for the global structural alteration of the ZP matrix, resulting in zona hardening and prevention of polyspermic fertilization. (Iwamoto et al., 1999).

The ZPB and/or ZPC glycoproteins are responsible for sperm attachment and binding, and are involved in induction of the acrosome reaction and subsequent penetration through the ZP (Töpfer-Petersen, 1999). Most of the carbohydrate structures of porcine ZPB and ZPC have been 
identified and $\mathrm{N}$ - and $\mathrm{O}$-glycosylation sites of the proteins were recognised (Töpfer-Petersen 1999; Nakano et al., 1996; 2001). N-glycans are bi/tri/tetra antennary oligosaccharides and are elongated with $\mathrm{N}$-acetyl-lactosamine repeats (Hokke et al., 1994). About $75 \%$ of the glycans are sialylated and/or carry $\mathrm{SO}_{3}-6 \mathrm{GlcNAc}$ in the lactosamine units, thereby contributing to the acidity of the glycoproteins. The predicted N-glycosylation sites of ZPB (three) and ZPC (four) are located in the ZP-domain. All three positions of ZPB at Asn203, Asn220 and Asn333 are occupied, whereas in ZPC, only three of four predicted sites at Asn124, Asn 146 and Asn271 carry glycan chains. (Kudo et al., 1998; Yonezawa et al., 1999). Three glycosylated threonine residues at position 156, 161 and 162 (ZPB) and two O-glycosylated sites at Ser293 and Thr303 (ZPC) have been identified (Yurewicz et al., 1991; Nakano and Yonezawa, 2001). O-linked chains are less heterogeneous than $\mathrm{N}$-linked chains and have unbranched structures carrying up to seven lactosamine repeats (Hokke et al., 1993) Comparison between bovine and murine species indicated that the glycosylation sites are not strictly conserved in the orthologous proteins (Amari et al., 2001; Easton et al., 2000). Although the oligosaccharide chains of the ZP glycoproteins have been implicated in the initial phase of fertilization; e.g. sperm-egg recognition and binding, the function of the carbohydrate structures has not been fully elucidated so far. Sacco et al. (1986) described the O-glycans from ZPB as ligands for corresponding sperm receptors, whereas Nakano and Yonezawa (2001) mapped the biological function to the neutral tri- and tetra-antennary $\mathrm{N}$-glycans linked to Asn220 of ZPB. Thereby, the non-reducing terminal ß-galactosyl residues of the $\mathrm{N}$-glycan chains play a crucial role in sperm recognition and binding events (Yonezawa et al., 2005) Interestingly, not only the carbohydrate structure itself, but also its position in the molecule and the three dimensional architecture of the ZP affect its binding functionality (Dunbar et al., 1994).

The zona glycoproteins build a structure that varies greatly among different oocytes of women (Schwartz et al., 2003) and appear as a network with multiple pores and hollows, created by a three-dimensional arrangement of filaments. The porous structure might be the result of cytoplasmic filaments from granulosa cells of the surrounding corona radiata, which penetrate the ZP and come in close contact with the oolemma during oogenesis. However, a more compact and smooth surface was also observed. According to Sundström (1982), this type was found in non-ovulatory, immature oocytes. Funahashi et al. (2000) showed that the outer surface of the ZP from in vivo matured oocytes had a mesh-like structure with numerous fenestrations and an uneven surface with microtrabecular appearance. In contrast, the outer surface of in vitro matured oocytes was more compact and smoother, which might indicate insufficient maturation. However, opinions about the surface structure of oocytes during the final stages of oogenesis are highly contradictory. Calafell et al. (1992) assumed a correlation between the type of surface morphology and the stage of maturity. Familiari et al. (1992) and Motta et al. (1991) described a net-like, porous surface mainly in mature oocytes, while immature and degenerated oocytes had a compact type with no pores. A porous structure was detected already at the germinal vesicle stage by Töpfer-Petersen (1999) and Sathananthan (1994), thus, these results were not confirmed. At this time, cytoplasmic filaments from the corona radiata penetrated the ZP surface and formed the net-like surface.

In a recent study, we investigated the fine structure of the porcine ZP during in vitro maturation and after fertilization, employing scanning electron microscopy (SEM) (Rath et al., 2005; H.W. Michelmann, P. Schwartz, D. Rath, E. Töpfer-Petersen unpublished). The morphology of the ZP was determined for fertilized and unfertilized oocytes, as well as early embryos. Oocytes were either immature or were matured in vivo or in vitro over a time period of $24 \mathrm{~h}$ and $48 \mathrm{~h}$, respectively. Pre-implantation embryos were either flushed from the female genital tract after in vivo development or cultured in vitro after IVF. 
Four different categories were identified for the surface structures. Type I represented a distinct net-like structure with numerous pores and hollows, which were arranged on the surface like a mesh. The zona of type II had a rough surface, sometimes folded and riddled with cracks and pores. The net-like structure had totally disappeared. A relatively smooth ZP exterior, that was divided by a net-like structure, but without or with only few pores characterized zona type III. In zona type IV, no pores or hollows nor any net-like structure were identified. They seemed to be fused to form an even or sometimes wavy surface.

Analysis of either immature, in vivo matured, or in vitro matured oocytes showed that all oocytes exhibited extremely heterogeneous zona morphologies with no clear trend. Only immature oocytes frequently showed the net-like, porous morphology of type I. Type IV surfaces with a compact and smooth appearance were rare. After maturation, in vivo and in vitro oocytes had a more compact and non-craggy ZP of Type III and IV. The distribution pattern of spermatozoa on the ZP was extremely variable, and sperm penetration into the ZP seemed not to be an active process solely of the spermatozoa. The ZP, as well, was actively involved in this process by overgrowing the sperm head with zona material. The effect of acrosin release on the zona surface was sporadically visible (Fig. 2).

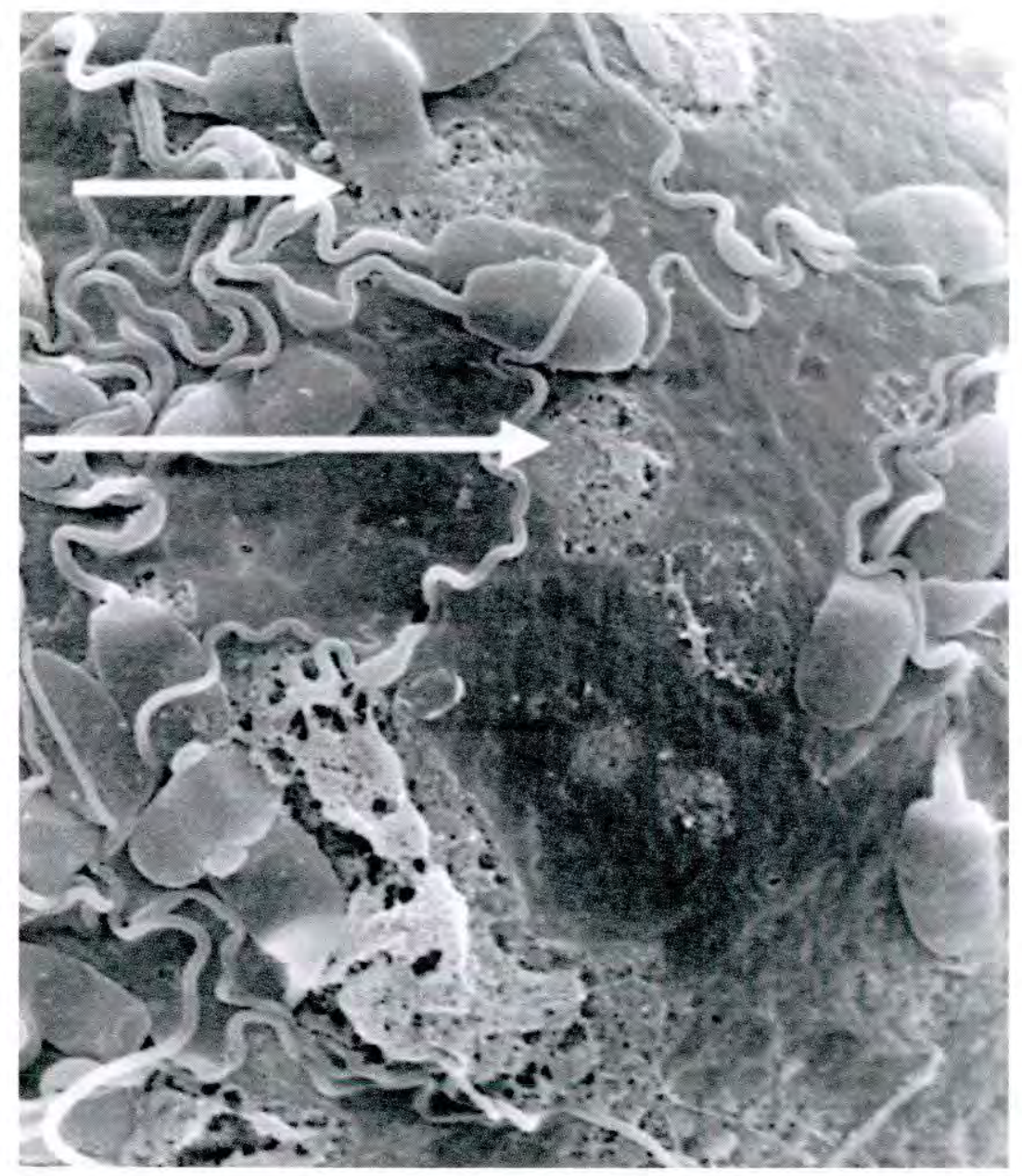

Fig. 2 SEM image of a porcine zygote (arrows indicate presumable effects of acrosin on the sperm surface) 
In comparing the ZP morphology of in vivo and in vitro produced embryos from zygote stage to the hatched blastocyst stage, it became obvious that the zona surface changed during embryonic development from a porous structure to the more compact and smooth surface of zona type IV, whereas the surface morphology of in vitro produced embryos from different developmental stages was more or less homogeneous. More than $70 \%$ of all embryonic stages revealed a compact and smooth ZP with hardly any pores, cracks or net-like structures. Independent of their origin, a complete change in surface structures was obvious between oocytes and embryos. While a majority of oocytes showed type III and IV morphologies (no pores, compact), zygotes and embryos up to the 4-cell stage had a more porous, net-like structure. Compact structures are more often visible, in addition to all the other structural types at the blastocyst stage (Fig. 3).
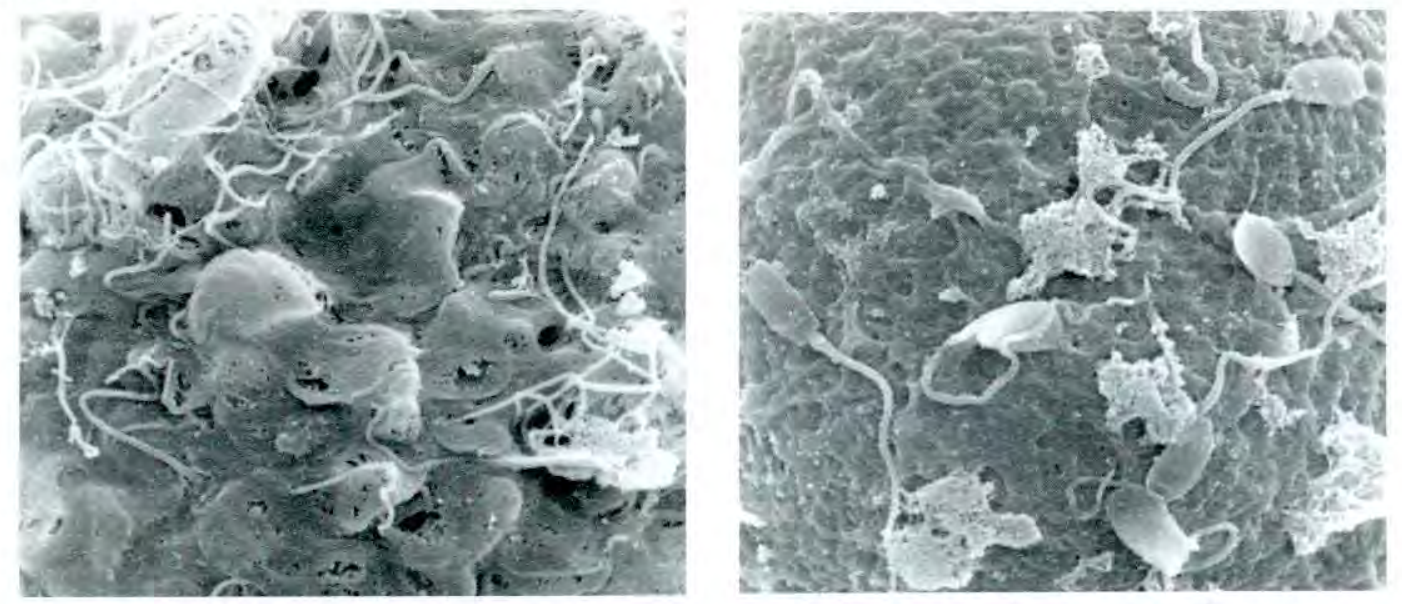

Fig. 3 Porcine blastocysts after in vivo (left image) and in vitro (right image) fertilization. Sperm integration into the ZP is tighter after in vivo fertilization.

Another interesting aspect was the kind of sperm binding to the ZP. During the first days of embryogenesis in vivo, the number of trapped spermatozoa increased with ongoing embryo development in spite of a zona block. Spermatozoa were deeply integrated into zona material; only their tails were visible on the ZP surface. In contrast, in vitro produced embryos had no increase in sperm numbers trapped in the ZP due to the principle of the IVF system, in which the fertilization medium is washed from presumed zygotes after $18 \mathrm{~h}$. However, in contrast to in vivo produced embryos, spermatozoa were very loosely attached and did not invade deeply into the ZP.

We recently established a special spermatozoa/ZP binding test (Rath et al., 2005) and flow cytometric assay (E. Töpfer-Petersen, unpublished) to demonstrate functional differences between immature and mature oocytes based on the ability to induce the acrosome reaction. Ejaculated, precapacitated sperm were co-cultured with intact ZP or solubilized ZP glycoproteins from immature and in vitro matured oocytes. The acrosome reaction was demonstrated by fluorescein isothiocyanate (FITC)-conjugated Peanut agglutinin (PNA) staining (Cross and Meizel, 1989). A double stain of FITC-PNA and propidium iodide (PI) was used to evaluate the acrosome reaction and sperm viability in parallel by the flow cytometric assay. Solubilised ZP glycoproteins exert an accelerating effect on the dynamics of membrane changes revealed by FITCPNA, thereby demonstrating the ongoing acrosome reaction. This effect occurred with ZP glycoproteins isolated from oocytes in both the GV and the MII stages. However, the maximal response was obtained with ZP proteins from the MII-stage oocytes, which induced an acrosome 
reaction at about twofold higher rates than the GV stage oocytes (Fig. 4). An effect in the same order of magnitude occurred by using the sperm/ZP binding test in the laser scanning confocal microscope. From these data, it can be concluded that the ZP undergoes maturation processes that influence the interaction potentials of the oocytes with the sperm surface.
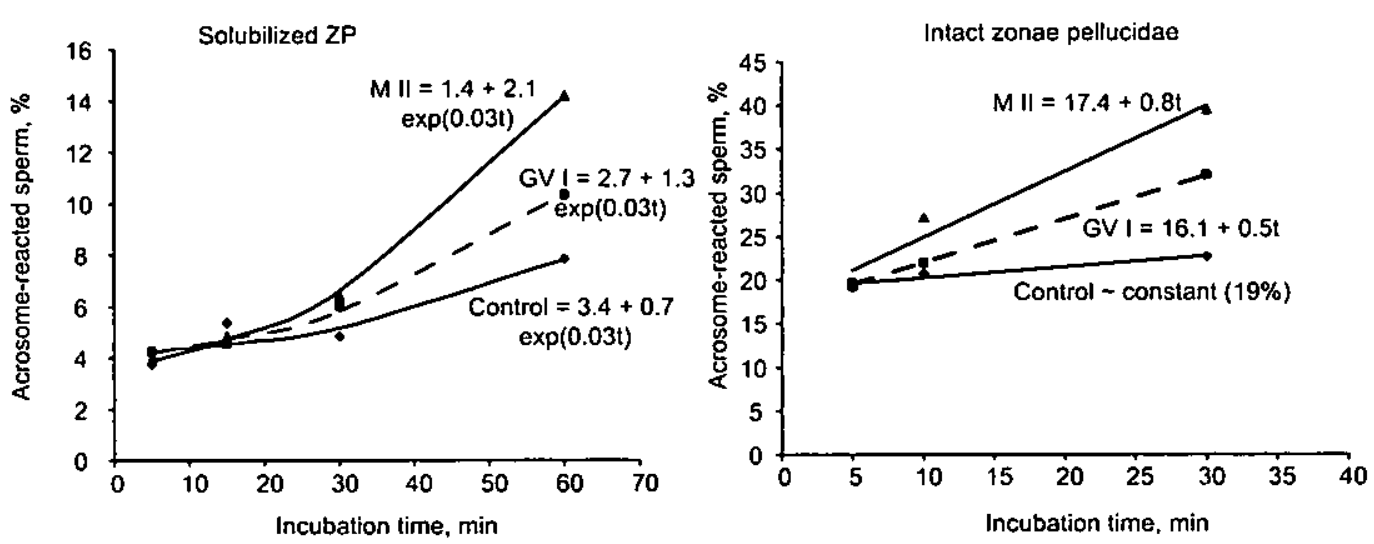

Fig. 4 Time dependence of zona pellucida-induced acrosome reaction (FITC-PNA, measured by flowcytometry). Increase in the percentage of the acrosome reacted sperm was about two-fold higher when $48 \mathrm{~h}$-matured oocytes were used compared to immature oocytes

In order to elucidate the mechanisms behind this, ZP of immature and mature oocytes were analyzed by two-dimensional polyacrylamide gel electrophoresis (2D-PACE). Interestingly, after maturation, ZPA moved $0.8 \mathrm{pl}$ units and ZPB/ZPC moved $1.3 \mathrm{pl}$ units to the anode indicating increased acidity compared to the $\mathrm{pl}$ of immature ZPA. In order to amplify the amount of proteins, glycoproteins were detected after 2D-PAGE and transferred to polyvinylidene difluoride (PVDF) membranes with the lectin Anguilla anguilla agglutinin (AAA) that recognizes fucose structures (Fuc- $\alpha$ (1-6)-GlcNAC) of all ZP N-glycans. An enhanced chemiluminescence detection system was used for visualization. In this case, the pl shift of ZPB/ZPC even reached $2 \mathrm{pl}$ units. These results show that the ZP undergoes biochemical changes in the final maturation phase of the oocyte prior to fertilization.

Importantly, so far, there were no differences between GVI and MII stages in the oligosaccharide pattern or degree of sialylation (data not shown) of the ZP. However, there is evidence that increasing sulfation of the oligosaccharides during the maturation phase is mainly responsible for acidification of porcine ZP glycoproteins. Concanavalin A agglutinin (Con A) binding demonstrated the dominant existence of mannose in diantennary complexes and the occurrence of oligomannosyl chains in ZPA, but not in ZPB/ZPC. Use of the lectins, Sambucus nigra agglutinin (SNA), Maackia amurensis agglutinin II (MAA II) and Amaranthus caudatus agglutinin (ACA), revealed the presence of differently linked sialic acids that presumably produce the shift in acidity. Now, the complete information on the carbohydrate structures and the glycosylation pattern of the three porcine ZP glycoproteins and a sensitive MS-based technology are available and may provide the basis to study the underlying mechanisms of maturation dependent glycan alterations in the pig. 


\section{Spermatozoa}

The main task of spermatozoa is to transport the male DNA located in the sperm head into the female oocyte. Before spermatozoa and oocytes can communicate, spermatozoa must undergo capacitation. Capacitation involves several steps that gradually change the sperm membranes during the transport through the female genital tract (Yanagimachi, 1994). It is characterized by removal of epididymal and seminal plasma proteins (Oliphant 1976; Johnson and Hunter, 1972; Reyes et al., 1975) as well as by a well-defined biochemical alteration of sperm surface proteins. This leads to higher fluidity of the sperm membranes ( $O^{\prime}$ Rand, 1979). Such alterations induce membrane fusions and cause protein poor areas of high fluidity on the sperm surface. Molecular events initiating capacitation have been partly elucidated and include removal of cholesterol from the sperm plasma membrane, modifications in plasma membrane phospholipids, and fluxes in $\mathrm{Ca}^{2+}$ and other ions that alter the sperm membrane potential. Furthermore, tyrosine phosphorylation of proteins that are involved in induction of hyperactivation and acrosome reaction, increase. The increase in tyrosine phosphorylation is dependent on the presence of serum albumin, $\mathrm{Ca}^{2+}$ and $\mathrm{HCO}_{3}$ (Visconti et al., 1995). It was demonstrated in mouse that glucose, but not lactate and pyruvate, is necessary to promote tyrosine phosphorylation. (Travis et al., 2001; Urner et al., 2001).

\section{Zona pellucida binding proteins}

Primary binding between capacitated spermatozoa and ZP involves many specialized molecules. The primary structures in some binding proteins have been elucidated, but, in most cases, the binding domain has not been characterized and the contribution of primary and/or secondary binding remains speculative. In the following paragraphs major characteristics of the binding proteins are summarised:

ß1,4 Galactosyltransferase (GalTase) is an integral protein of the spermatozoa surface of many mammals (Larson and Miller, 1997). It binds to specific terminal N-glucosamines of the ZP and supports gamete binding as well as activation of $G$ proteins in sperm membranes, which assists phosphorylation to induce the acrosome reaction. Interestingly GalTase-knock-out mice were still fertile, but less effective in sperm penetration (Shur, 1998). This indicates that primary binding and induction of acrosome reaction are mediated through several receptors.

Another integral sperm protein, as shown in mice, is p95. It cooperates with GalTase to induce a signal cascade. Murine sp56 is a peripheral membrane protein that binds to O-glycosidal carbohydrate chains of ZPC and interacts with primary binding sites (Cheng et al., 1994). Sp17 is a low molecular weight membrane protein belonging to, so-called, rabbit sperm antigens (RSA) and it binds to the ZP by a sulphate recognition mechanism ( $O^{\prime}$ Rand et al., 1988; Abbdullah et al, 1991). Sp 17 also seems to bind specifically to galactose (Richardson et al., 1994). Like SP17, membrane binding protein (MBP), belongs to C-type lectins (Drickramer, 1993).

PH 20 is necessary for secondary binding events (Yudin et al.; 1999) as was shown in guinea pigs and primates (Primakoff et al,; 1997; Lin et al., 1993). It is expressed in testis and is located on the posterior sperm head region and the inner acrosomal membrane (Tung et al., 1997). PH 20 has hyaluronidase activity and supports penetration of the sperm cell through the ZP. Its functionality during secondary binding was inhibited by antibody (Hunnicutt et al., 1996). In addition, arginine units contribute to sperm binding.

$\mathrm{P} 47$ is a protein bound to the peripheral sperm membrane with high homology in different mammalian species (Ensslin et al., 1998; Töpfer-Petersen, 1999). Its structure consists of two epidermal growth factor (EGF) domains at the $\mathrm{N}$-terminal end and two large C-terminal domains, which are similar to blood clotting factors $V$ and VII. A second EGF-like domain includes a RGD (Arg-Gly-Asp tripeptide) motif as seen in several integrin ligands (Eble and Kühn, 
1997). The function of $P 47$ still remains unclear; however, because they were in spermatozoa, which were trapped in the ZP, and have affinity for glycoproteins, they may participate in primary binding. After the acrosome reaction, $\mathrm{p} 47$ disappears, and therefore, does not contribute to secondary binding events. The homologous protein in the mouse, SED1, binds to the ZP of unfertilised eggs. SED1 null mice are subfertile and their sperm were unable to bind to the ZP in vitro (Ensslin and Shur, 2003). Proteins with the bimotif, EGF repeats and discoidin domains, mediate a variety of cell-matrix interactions (Shur et al., 2004). P47/SED1 may, therefore, function in mammals as an intermediary between the sperm surface and the ZP.

Proacrosin is produced from pre-proacrosin. During acrosome reaction and when induced by a pH increase, it transformed into B-Acrosin under the control of the ZP (Töpfer-Petersen and Cechova, 1990). B-Acrosin promotes digestion of the ZP during sperm migration through this matrix. In addition to proteolytic characteristics, proacrosin and acrosin have high polysulphatemediated affinity to the ZP, which is based on interactions between the positively charged amino acids of proacrosin and acrosin and the sulphate groups of $\mathrm{N}$ - and $\mathrm{O}$-glycans containing lactosamines (Jansen et al., 1995).

Zonadhesin is a transmembrane protein that mediates sperm-zona binding. It has been isolated from porcine spermatozoa. Although species-specific differences are known, four domains are similar. These are called MAM domain, mucin like domain, D-domain and EGF like domain (Gao and Garbers, 1998). A precursor of zonadhesin is produced in the testis. During sperm maturation in the porcine epididymis, it forms a dimer composed of 2 p45 and 1 p 105 subunits. The dimer is connected by disulfide bridges (Lea et al., 2001). Zonadhesin participates in ZP binding and initial recognition.

Spermadhesins represent a novel group of lectins and belong to a superfamily of developmentally regulated proteins, all of which share the, so-called, CUB domain within a modular structure (Bork and Beckmann, 1993). The spermadhesins spanning 110 - 133 amino acids form a subgroup comprising a single CUB domain. The overall structure of the domain consists of a B-sandwich build up by two sheets, each containing four anti-parallel and one parallel B-strand. (Romero et al., 1997; Töpfer-Petersen et al,. 1998). Spermadhesins have been identified in, different species. The greatest diversity of this family was found in the pig (Töpfer-Petersen et al., 1998) with five closely related genes. Two spermadhesin genes were present in cattle and inactive copies were still detected in the human, chimpanzee and dog, while the corresponding region was lost from rodent genomes (Haase et al., 2005). The spermadhesins, AWN, AQN1 and $A Q N-3$, have been isolated from porcine spermatozoa. In addition, these proteins, the $\mathrm{N}$ terminally acetylated AWN isoform, the glycosylated isoforms of AWN and AQN-3, as well as PSP-1 and PSP-2 were identified in seminal plasma, which comprise the bulk of seminal plasma proteins (Solis et al., 1997; Calvete et al., 1993a, 1993b, 1994; Sanz et al. 1992,1993). In equine spermatozoa, HSP-7, a homologue of AWN, was described by Reinert et al., (1996), and in bovine spermatozoa, aSFP (acidic seminal fluid protein), newly termed SPADH1, and Z13 (SPDH2) were characterized by Wempe et al.(1992) and Tedesch et al.(2000). Other major sites of spermadhesin production are the seminal vesicle glands and prostate. Spermadhesins are also expressed in the epididymis as shown by RT-PCR. However, only the mature protein, AWN, was identified in the cauda epididymis by SDS-PAGE and Western blot (EkhlasiHundrieser et al., 2002). This explains why AWN is the only spermadhesin that is already attached on epididymal spermatozoa, whereas the spermadhesins $A Q N-1$ and $A Q N-3$ are added to the sperm surface during ejaculation. $A W N, A Q N-1$ and $A Q N-3$ represent the sperm-binding spermadhesins, whereas the porcine spermadhesins (PSP) do not specifically interact with the sperm surface (Töpfer-Petersen et al., 1998). AWN is located on the acrosomal cap of porcine spermatozoa, whereas equine spermatozoa carry it on the equatorial segment of the sperm 
head. (Töpfer-Petersen et al., 1995). Interestingly, AWN is also expressed in the female genital tract, namely, in the utero-tubal junction and oviductal ducts (Ekhlasi-Hundrieser et al., 2002). Spermadhesins are multifunctional proteins and may participate in many biochemical processes. Their ability to bind to phospholipids ( $A W N$ and AQN-3), serine-proteinase-inhibitors and glycosaminoglycans (GAG) (Sanz et al., 1992b) may be responsible for their tight interaction with the sperm surface and participation in capacitation as negative and positive regulating factors (Töpfer-Petersen et al., 1998). The most striking feature of porcine spermadhesins is their carbohydrate-binding ability. These sperm-binding proteins recognize non-reducing terminal $\alpha$ - and $B$-galactose in O- and N-glycans (AWN and AQN's) (Töpfer-Petersen et al., 1998) and oligomannosyl chains (AQN-1) (Ekhlasi-Hundrieser et al., 2005). During sperm transport through the female genital tract, spermadhesins ( $A Q N-1)$ serve as receptors to bind spermatozoa to the epithelium lining the oviduct, which helps build up the sperm reservoir (Wagner et al., 2002; Ekhlasi-Hundrieser et al., 2005). Later, spermadhesins may play an important role in sperm-oocyte interaction in the oviduct. AWN was present in spermatozoa bound to the ZP in vivo (Rodriguez-Martinez et al., 1998). Since it is located on the apical region of the sperm head, it is assumed that AWN contributes to initiation of the first contact between gametes, and may be part of the proposed multimeric receptor system (Shur, 1998).

\section{Conclusion}

Sperm-oocyte interaction is an important event leading to establishment of new life. Although in vitro embryo production has been established in several species and many aspects of gamete recognition and interaction have been elucidated on a structural, biochemical and functional level, major aspects of the fertilization process remain speculative or unknown. However, the basic tools to enable a better insight into gamete interaction have been established for the porcine, as shown above, and will help to better understand fertilization. Occurrence of polyspermy is critical, especially in porcine in vitro embryo production. With the understanding of sperm selection during transport through the female genital tract and characterization of the fertilizing sperm population, which are based on the information provided above, monospermic fertilization will be established in the foreseeable future in the porcine too. In parallel, development of indicators of maximal maturation of oocytes are required, since it is obvious that not only the nucleus and the cytoplasm require adequate maturation to become fully competent, but the ZP also undergoes a maturation process, which seems to be incomplete after employing the usual in vitro maturation protocols.

\section{References}

Abdullah M, Widren EE and $\mathbf{O}^{\prime}$ Rand MG (1991) A mammalian sperm lectin related to rat hepatocyte lectin$2 / 3$. Purification from rabbit testis and identification as a zona binding protein Molecular and Cellular Biochemistry $103 \quad 155-161$

Amari S, Yonezawa N, Mitsui S, Katsumata T, Hamano S, Kuwayama M, Hashimoto Y, Suzuki A, Takeda Y and Nakano $M$ (2001) Essential role of the nonreducing terminal alpha-mannosyl residues of the $\mathrm{N}$-linked carbohydrate chain of bovine zona pellucida glycoproteins in spermegg binding. Molecular Reproduction and Development 59 221-226
Bauskin AR, Franken DR, Eberspächer $U$ and Donner $P$ (1999) Characterization of human zona pellucida glycoproteins Molecular Human Reproduction 5543 . 540

Bleil JD and Wassarman PM (1990) Identification of a ZP3-binding protein on acrosome-intact mouse sperm by photoaffinity crosslinking Proceedings of the National Academy of Sciences of the United States of America 1990 5563-5567

Bookbinder LH, Cheng A and Bleil JD (1995) Tissue- and species-specific expression of $\mathrm{sp} 56$, a mouse sperm fertilization protein Science 269 86-89 
Bork P (1993) A trefoil domain in he major rabbit zona pellucida protein Protein Science 2 669-670

Bork P and Beckmann G (1993): The CUB domain: A widespread module on developmentally regulated proteins Journal of Molecular Biology $231539-545$

Bork P and Sander C (1992) A large domain common to sperm receptors (Zp2 and ZP3) and TGF-\{3-type III receptor FEBS Letters 300 237-240

Burks DJ, Carballada R, Moore HD and Saling PM (1995) Interaction of a tyrosine kinase from human sperm with the zona pellucida at fertilization Science 269 83-86

Calafell JM, Nogues C, Ponsa M, Santalo / and Egozcue $J(1992)$ Zona pellucida surface of immature and in vitro matured mouse oocytes: Analysis by scanning electron microscopy Journal of Assist Reproductive Genetic 9 365-372.

Calvete IJ, Sanz L, Dostalova $Z$ and Töpfer-Petersen $E$ (1993a) Characterization of AWN-1 glycosylated isoforms helps define the zona pellucida and serine proteinase inhibitor-binding region on boar spermadhesins FEBS Letters 334 37-40

Calvete J, Solis D, Sanz L, Diaz-Maurino T and TöpferPetersen E (1994) Glycosylated boar spermadhesin AWN-1 isoforms: Biological origin, structural characterization by lectin mapping, localization of $\mathrm{O}$ glycosylation sites, and effect of glycosylation on ligand binding Biological Chemistry Hoppe Seyler $375667-673$

Calvete IJ, Solis D, Sanz. L, Diaz-Maurino T, Schäfer W, Mann K and Töpfer-Petersen E (1993b) Characterization of two glycosylated boar spermadhesins European Journal of Biochemistry 218 719-725

Cheng A, Le T, Palacois P, Bookbinder LH, Wassasman PM, Suziki F and Bleil JD (1994) Sperm-egg recognition in the mouse: characterization of $\mathrm{sp56}$, a sperm protein having specific affinity for ZP3 Journal of Cell Biology $125867-878$

Cross NL and Meizel S (1989) Minireview: Methods for evaluating the acrosomal status of mammalian sperm. Biology of Reproduction 41 635-641

Dostalova Z, Calvete IJ, Sanz L and Töpfer-Petersen E (1995) Boar spermadhesin AWN-1. Oligosaccharide and zona pellucida binding characteristics European Journal of Biochemistry $230 \quad 329-336$

Drickramer K (1993) Ca2 + dependent carbohydraterecognition domain in C-type mannose binding protein Current Opinion in Structural Biology 3 393400

Dunbar BS, Avery S, Lee V, Prasad SV, Schwahn D, Schwoebel E, Skinnern S and Wilkens B (1994) The mammalian zona peltucida: Its biochemistry, immunochemistry, molecular biology and developmental expression Reproduction, Fertility and Development $659-76$

Easton RL, Patankar MS, Lattanzio FA, Leaven TH, Morris HR, Clark Gf and Dell A (2000) Structural analysis of murine zona pellucida glycans. Evidence for the expression of core 2-type O-glycans and $\mathrm{Sd}(\mathrm{a})$ antigen fournal of Biological Chemistry 275 7731-7742
Eble JA and Kühn K (1997) Integrin-Ligand Interactions Springer Verlag, New York

Ekhlasi-Hundrieser M, Gohr K, Wagner A, Tsolova M, Petrunkina $A$ and Töpfer-Petersen $E$ (2005) Spermadhesin $A Q N-1$ is a candidate receptor molecule involved in the formation of the oviductal sperm reservoir in pig Biology of Reproduction (in press)

Ekhlasi-Hundrieser $M$, Sinowatz F, Creiser de Wilke I, Waberski $D$ and Töpfer-Petersen $E$ (2002) Expression of spermadhesin genes in porcine male and female genital tracts Molecular Reproduction and Development $6132-41$

Ensslin M, Vogel T, Calvete JJ, Thole HH, Schmidtke J, Matsuda T and Töpfer-Petersen E (1998): Molecular cloning and characterization of $\mathrm{P} 47$, a novel boar sperm associated zona pellucida-binding protein homologous to a family of mammalian secretory proteins Biology of Reproduction 58 1057-1064

Ensslin MA and Shur BD (2003) Identification of mouse sperm SED1, a bimotif EGF repeat and discoidindomain protein involved in sperm-egg binding Cell $114405-417$

Familiari G, Nottola SA, Macchiarelli G, Micara G, Aragona C and Motta PM (1992) Human zona pellucida during in vitro fertilization: An ultrastructural study using saponin, ruthenium red, and osmiumthiocarbohydrazide Molecular Reproduction and Development 32 51-61

Funahashi $H$, Ekwall $H$ and Rodriguez-Martinez $\mathbf{H}(2000)$ Zona reaction in porcine oocytes fertilized in vivo and in vitro seen with scanning electron microscopy Biology of Reproduction 63 1437-1442

Gao Z and Garbers DL (1998) Species diversity in the structure of zonadhesin, a sperm specific membrane protein containing multiple cell adhesion moleculelike domains Journal of Biological Chemistry 273 3415-3421

Gong X, Dubois DH, Miller DJ Shur BD (1995) Activation of a G-protein complex by aggregation of B-1,4 galactosyltransferase on the surface of sperm Science 269 1718-1721

Haase B, Schlötterer C, Ekhlasi-Hundrieser M, Kuiper H, Dustl O, Töpfer-Petersen $E$ and Leeb T (2005) Evolution of the spermadhesin gene family Gene (in press)

Harris JD, Hibler DW, Fonteno GK, Hsu KT, Yurewiz EC and Sacco AG (1994) Cloning and characterisation of zona pellucida genes and CDNAs from a variety of mammalian species: ZPA, ZPB and ZPC families DNA Sequence 4 361-393

Hasegawa A, Koyama K, Okazaki Y, Sugimoto $M$ and Isojima $S$ (1994) Amino acid sequence of a porcine zona pellucida glycoprotein ZP4 determined by peptide mapping and cDNA cloning journal of Re production and Fertility 100 245-255

Hokke CH, Damm JBI, Penninghof RJ, Aitken JP and Vliegenhart JFG (1993) Structure of O-linked carbohydrate chains of porcine zona pellucida glycoproteins European Journal of Biochemistry 221 491-512

Hokke CH, Damm JBL, Penninkhof B, Aitken RJ, Kamerling IJP and Vliegenthart FG (1994) Structure of the O-linked carbohydrate chains of porcine zona 
pellucida glycoproteins European Journal of Biochemistry $221491-512$

Hunnicutt GR, Primakoff P and Myles DG (1996) Sperm surface protein $\mathrm{PH}-2 \mathrm{O}$ is bifunctional: one activity is a hyaluronidase and a second, distinct activity is required in secondary binding Biology of Reproduction 55 80-86

Iwamoto K, Ikeda K, Yonezawa N, Noguchi S, Kudo K, Hamano S, Kuwayama $M$ and Naka M (1999) Disulfide formation in bovine zona pellucida glycoproteins during fertilization: Evidence for the involvement of cysteine cross-linkages in hardening of the zona pellucida Journal of Reproduction and Fertility 117 395-402

Jansen S, Ekhlasi-Hundrieser $M$ and Toepfer-Petersen $E$ (2001) Sperm Adhesion Molecules: Structure and Function Cell Tissue Organs 168 82-92

Jansen S, Quingley M, Reik W and Jones J (1995) Analysis of polysulphate-binding domains in porcine proacrosin, a putative zona adhesion protein from mammalian spermatozoa Developmental Biology 39 501-501

Johnson WL and Hunter AG (1972) Seminal antigens: their alteration in the genital tract of female rabbits and during partial in vitro capacitation with B-amylase and B-glucoronidase. Biology of Reproduction $7332-340$

Kouba AJ, Abeydeera I.R, Alvarez IM, Day BN and Buhi WC (2000) Effects of the porcine oviduct-specific glycoprotein on fertilization, polyspermy, and embryonic development in vitro Biology of Reproduction $63 \quad 242-250$

Kudo K, Yonezawa N, Katsumata T, Aoki H and Nakano $M$ (1998) Localization of carbohydrate chains of pig sperm ligand glycoproteins ZPB of egg zona pellucida European Journal of Biochemistry $252492-499$

Larson IL and Miller DJ (1997) Sperm from a variety of mammalian species express beta 1,4 galactosyltransferase on their surface Biology of Reproduction $57442-453$

Lea IA, Sivashanmugam $P$ and $O^{\prime}$ Rand MG (2001): Zonadhesin: characterization, localization and zona pellucida binding Biology of Reproduction 651691 1700

Leyton 1, L.eGuen P, Bunch D and Saling PM (1992) Regulation of mouse gamete interaction by a sperm tyrosine kinase Proceedings of the National Academy of Sciences of the United States of America 89 11692-11695

Lin Y, Kimmel LH, Myles DG and Primakoff P (1993) Molecular cloning of the human and monkey sperm surface protein $\mathrm{PH}-20$ Proceedings of the National Academy of Sciences of the United States of America 90 10071-10075

Lindsay LL and Hedrick JL (2004) Proteolysis of Xenopus laevis egg envelope ZPA triggers envelope hardening Biochemical and Biophysical Research Communications 324 648-654

Maxwell WM and Johnson LA (1999) Physiology of spermatozoa at high dilution rates: the influence of seminal plasma Theriogenology 52 1353-1362
Motta PM, Familiari G, Nottola SA, Micara G and Aragona C (1991) Micro-structural events of human egg investments during in vitro fertilisation. Ultrastructure of the Zona pellucida and the cumulus oophorus Bulletin del'Association Anatomy 7589 91

Nakano $M$ and Yonezawa $N$ (2001) Localization of sperm ligand carbohydrate chains in pig zona pellucida glycoproteins Cell Tissues Organs 168 65-75

Nakano $M$, Yonezawa $N$, Hatanaka $\mathbf{Y}$ and Noguchi $S$ (1996) Structure and function of the N-linked carbohydrate chains of pig zona pellucida glycoproteins Journal of Reproduction and Fertility 50 25-34

$O$ 'Rand MG, Widgren EE and Fischer SJ (1988) Characterization of the rabbit sperm membrane autoantigen, RSA, as a lectin-like zona binding protein Developmental Biology 129 231-240

Oliphant $G$ (1976) Removal of sperm bound seminal plasma components as a prerequisite to induction of the rabbit acrosome reaction Fertility and Sterility 27 28-38

Prather RS and Day BN (1998) Practical considerations for the in vitro production of pig embryos Theriogenology 49 23-32

Primakoff P, Woolman-Gamer L, Tung KS and Myles DG (1997) Reversible contraceptive effect of PH-20 immunization in male guinea pigs Biology of Reproduction 56 1142-1146

Rath D, Topfer-Petersen E, Michelmann HW, Schwartz $P$ and Ebeling S (2005) Zona pellucida characteristics and sperm binding patterns of in vivo and in vitro produced porcine oocytes inseminated with differently prepared spermatozoa Theriogenology 63352 362

Reinert M, Calvete J, Sanz L, Mann K and Töpfer-Petersen E (1996) Primary structure of stallion seminal plasma protein HSP-7, a zona-pellucida-binding protein of the spermadhesin family. European Journal of Biochemistry 242 636-640

Reyes A, Oliphant G and Brackett BG (1975) Partial purification and identification of a reversible decapacitation factor from rabbit seminal plasma Fertility and Sterility 26 148.157

Richardson RT, Yamasaki N and O'Rand MG (1994) Sequence of rabbit sperm zona pellucida binding protein and localization during acrosome reaction Developmental Biology 165 688-701

Rodriguez-Martinez $\mathrm{H}$, lborra $A$, Martinez $P$ and Calvete IJ (1998) Immunoelectronmicroscopic imaging of spermadhesin AWN epitopes on boar spermatozoa bound in vivo to the zona pellucida Reproduction, Fertility and Development 10 491-497

Romero A, Romao MJ, Varela PF, Kolln I, Dias JM, Carvalho AL, Sanz L, Topfer-Petersen E and Calvete IJ (1997) The crystal structures of two spermadhesins reveal the CUB-domain fold Nature Structural Biology 4 783-788

Sacco AG, Yurewicz EC and Subramanian MG (1986) Carbohydrate influences the immunogenic and antigenic characteristics of the ZP3 macromolecule $(\mathrm{Mr}$ 55000 ) of the pig zona pellucida Journal of Repro- 
duction and Fertility 76 575-586

Sanz L, Calvete J, Jonakova $V$ and Töpfer-Petersen $E$ (1992b) Boar spermadhesins $A Q N-1$ and $A W N$ are sperm-associated acrosin inhibitor acceptor proteins FEBS Letters 300 63-66

Sanz L, Calvete IJ, Mann K, Gabius HJ and Töpfer-Petersen E (1993) Isolation and biochemical characterization of heparin-binding proteins from boar seminal plasma: a dual role for spermadhesins in fertilization Molecular Reproduction and Development 35 37.43

Sanz L, Calvete IJ, Mann K, Schafer W, Schmid ER, Amselgruber $W$, Sinowatz F, Ehrhard $M$ and TopferPetersen E (1992) The complete primary structure of the spermadhesin AWN, a zona pellucida-binding protein isolated from boar spermatozoa FEBS Letters 300 213-218

Sanz L, Calvete IJ, Schafer W, Mann K and Töpfer-Petersen E (1992a) Isolation and biochemical characterization of two isoforms of a boar sperm zona pellucida-binding protein Biochimica et Biophysica Acta 1119127. 132

Schwartz P, Hinney B, Nayudu PL and Michelmann HW (2003) Oocyte-sperm interaction in the course of IVF: a scanning electron microscopy analysis Reproductive Bio Medicine Online 7 83-88

Shur B (1998) Is a sperm galactosyltransferase a signaling subunit of a multimeric gamete receptor? Biochemical and Biophysical Research Communications 250 537-543

Shur BD and Neely CA (1988) Plasma membrane association, purification, and partial characterization of mouse sperm beta 1,4-galactosyitransferase Journal of Biological Chemistry 263 17706-11714

Shur BD, Ensslin MA and Rodehoeffer C (2004) SED1 function during mammalian sperm-egg adhesion Current Opinion in Cell Biology 16, 477-485

Sinowatz F, Topfer-Petersen E and Calvete JJ (1997) Glycobiology of fertilization. In Glycosciences- Status and perspectives pp 595-610 Eds HJ Gabius and S Gabius. Weinheim Chapman and Hall, London

Solis D, Jimenez-Barbero J, Kaltner H, Romero A, Siebert HC, von der Lieth $\mathrm{CW}$ and Gabius HJ (2001) Towards defining the role of glycans as hardware in information storage and transfer: basic principles, experimental approaches and recent progress Cells Tissues Organs 168 5-23

Sundström P (1982) Interaction between spermatozoa and ovum in vitro. In Atlas of human reproduction by scanning electron microscopy pp 225-230 Eds. E Hafez and P Kenemans. MTP press, Lancaster, Boston, The Hague

Tedesch G, Oungre E, Mortarino M, Negri A, Maffeo G and Ronchi $\mathbf{S}(2000)$ Purification and primary structure of a new bovine spermadhesin European Journal of Biochemistry 267 6175-6179

Töpfer-Petersen E (1999) Carbohydrate-based interactions on the route of a spermatozoon to fertilization Human Reproduction Update 5 314-329

Tópfer-Petersen E and Calvete \&J (1995) Molecular mechanisms of the interaction between sperm and the zona pellucida in mammals: studies on the pig Interna- tional Journal of Andrology 18 Suppl 2 20-26

Töpfer-Petersen E and Cechova D (1990) Zona pellucida induces conversion of proacrosin to acrosin International Journal of Andrology 13 190-196

Töpfer-Petersen E, Calvete JJ, Sanz I. and Sinowatz F (1995) Carbohydrate- and heparin-binding proteins in mammalian fertilization Andrologia 27 303-324

Töpfer-Petersen E, Romero A, Varela PF, EkhlasiHundrieser M, Dostalova Z, Sanz L and Calvete JJ (1998) Spermadhesins: a new protein family. Facts, hypothesis and perspectives Andrologia 30 217-224

Travis Al, Jorgez Cl, Merdiushev T, Jones BH, Dess DM, Diaz-Cueto L, Storey BT, Kopf GS and Moss SB (2001) Functional relationships between capacitation-dependent cell signaling and compartmentalized metabolic pathways in murine spermatozoa Journal of Biological Chemistry 276 7630-7636

Tung KS, Primakoff $P$, Woolman-Gamer $L$ and Myles DG (1997) Mechanism of infertility in male guinea pigs immunized with sperm $\mathrm{PH}-20$ Biology of Reproduction 56 1133-1141

Urner F, Leppens-Luisier $G$ and Sakkas D (2001) Protein tyrosine phosphorylation in sperm during gamete interaction in the mouse: the influence of glucose Biology and Reproduction 64 1350-1357

Visconti PE, Bailey JL, Moore GD, Pan D, Olds-Clarke P and Kopf GS (1995) Capacitation of mouse spermatozoa I. Correlation between the capacitation state and protein tyrosine phosphorylation Development 121 1129-1137

von Witzendorff D, Ekhlasi-Hundrieser M, Dostalova $Z$, Resch $M$, Rath D, Michelmann $H W$ and TöpferPetersen E (2004) Analysis of $\mathrm{N}$-linked glycans of porcine zona pellucida glycoprotein ZPA by MALDITof mass spectrometry: a contribution to understanding zona pellucida structure Glycobiology Advance Access published on December 21, 2004; doi: 10.1093/glycob/cwi022

Wagner A, Ekhlasi-Hundrieser M, Hettel C, Peterunkina A, Waberski D, Nimtz $M$ and Töpfer-Petersen E (2002) Carbohydrate-based interaction of oviductal sperm reservoir formation - studies in the pig Molecular Reproduction and Development 61 249-257

Wassarman PM (1990) Regulation of mammalian fertilization by zona pellucida glycoproteins journal of Reproduction Fertility 42 Suppl $79-87$

Wempe F, Einspanier K and Scheit KH (1992) Characterization by cDNA cloning of the mRNA of a new growth factor from bovine seminal plasma: acidic seminal fluid protein Biochemical and Biophysical Research Communications 183 232-237

Yonezawa N, Amari S, Takahashi K, Ikeda K, Imai FL, Kanai S., Kikuchi K and Nakano M (2005) Precipitation of non-reducing beta-galactosyl residues of the neutral $\mathrm{N}$-linked carbohydrate chains of porcine zona pellucida glycoproteins in sperm-egg binding Molecular Reproduction and Development 70 222227

Yonezawa N, Fukui N, Kudo K and Nakano M (1999) Localisation of neutral $\mathrm{N}$-linked carbohydrate chains in pig zona pellucida glycoproteins ZPC European Journal of Biochemistry 260 57-63 
Yudin Al, Vandevoort CA, Li MW and Overstreet JW (1999) PH-20 but not acrosin is involved in sperm penetration of the macaque zona pellucida Molecular Reproduction and Development 53 350-362

Yurewicz EC, Pack BA and Sacco AG (1991) Isolation, composition, and biological activity of sugar chains of porcine oocyte zona pellucida $55 \mathrm{kDa}$ glycoprotein Molecular Reproduction and Development 30 126-134

Zhang l, Musz LZ and Boyle MS (1991) Variations in structural and functional changes of staltion spermatozoa in response to calcium ionophore A23187 Journal of Reproduction and Fertility Suppl 44 199-205 